\title{
EL PROCESO A ESPURIO POSTUMIO ALBINO
}

\author{
Juan PÉREz CARRANDi \\ Profesor de Derecho romano \\ Real Centro Universitario María Cristina \\ Universidad Internacional de Valencia \\ Colaborador Honorífico del Departamento \\ de Derecho romano e Historia del Derecho \\ Facultad de Derecho \\ Universidad Complutense de Madrid \\ jcarrandi@rcumariacristina.com
}

\section{INTRODUCCIÓN}

La causa a Espurio Postumio Albino ha resultado un hecho histórico de primer nivel para el estudio del Derecho penal militar romano. En la actualidad, la información de que disponemos acerca del mundo militar romano es relativamente limitada, pues lo autores antiguos no prestaron en su momento gran atención hacia el grueso del ejército en relación con aspecto alguno, prefiriendo centrarse en la vida de afamados generales. El Derecho no ha sido aquí una excepción, y las referencias en torno a la legislación castrense tienden a ser escasas. Dicho esto, y para contextualizar, hemos de decir que el juicio a Espurio, creemos, aportará luz al respecto. El mismo tendrá lugar dentro de lo que fue la quaestio Mamilia; hablamos de un tribunal especial que nace con el objetivo de enjuiciar a un grupo de notables romanos que habían sido acusados públicamente en el 109 a. C. por el tribuno Cayo Mamilio Limetano por, presuntamente, haberse corrompido a través de diferentes sobornos provenientes del rey Yugurta. Roma había enviado en los últimos años al norte de África diferentes embajadas con el fin de imponer la estabilización del reino númida ante las guerras intestinas que se venían sucediendo en la región ${ }^{1}$.

\footnotetext{
${ }^{1}$ Hacía años que Numidia venía siendo víctima de una fuerte violencia interna, fruto de problemas en la sucesión al trono. Así, en el 117 y 116 a. C. la inestabilidad política hará que Hiempsal ocupe los dominios de Yugurta, resultando sin embargo una jugada fatídica para aquel, pues morirá a manos de este. Poco después, otro pretendiente al trono, Adherbal, temeroso de las aspiraciones de Yugurta, envía alarmado emisarios a Roma y consigue
} 
Señalaremos, por otra parte, cómo este tipo de procesos, el de las quaestiones, va a constituir toda una novedad en el ámbito procesal; y ello por una tendencia que va experimentando el sistema criminal, el cual tiende a aproximarse al ámbito público, al tiempo que se dota de consistencia y autonomía, en el último tercio de la República ${ }^{2}$. Sin embargo, lo que había existido hasta entonces eran los iudicia populi como causas ordinarias $^{3}$, los cuales caerán, entre otros motivos ${ }^{4}$ por el miedo creciente que prende entre la oligarquía, que empieza a ver en este tipo de procesos un escenario muy vulnerable frente a maniobras y presiones demagógicas 5 .

Los hechos llevan a afirmar que el sistema judicial romano entra en el último tercio del periodo republicano en una etapa de colapso. Ello es aprovechado por el Senado, que reacciona con prontitud y, con relación al tratamiento procesal de los delitos de mayor gravedad, decide abrogarse progresivamente el papel de tutor supremo de las instituciones republicanas frente a las amenazas al poder vigente. De este modo, se da inicio a la coexistencia entre los ya decadentes iudicia populi y las recién creadas asambleas senatoriales, las cuales, desde comienzos del siglo II a. C., empiezan a trabajar como quaestiones extraordinariae ${ }^{6}$. Este tipo de tribunales se erige como una respuesta provisional al tratamiento procesal del

con ello que el Senado mande al conflictivo reino una embajada para imponer el apaciguamiento general. La misión romana es de inmediato sobornada por Yugurta, que consigue que la legación se limite a imponer la delimitación de dos dominios en el reino, uno asignado a Yugurta, y otro a Adherbal. Pero en el 113 a. C. Yugurta ocupa el territorio de Adherbal, quien vuelve a enviar a Roma una misión de auxilio. A su vez, los romanos mandan otra embajada a la conflictiva región, pero una vez más, esta vuelve a ser sobornada por el monarca, quien acaba matando a Adherbal y también a gran cantidad de publicani [G. FERNÁNDEZ HERNÁNDEZ, «El estallido y primera fase de la guerra de Yugurta y su incidencia en la política exterior romana», Baetica: Estudios de Arte, Geografía e Historia, núm. 25 (2003), p 470].

2 C. Gioffredi, I principi del diritto penale romano, Torino, Giappichelli, 1970, p. 17.

3 V. GIUfFrè, Il «Diritto penale» nell esperienza romana, Napoli, Jovene, 1989, p 37. Será tras la segunda Guerra Púnica cuando, dentro de un marco generalizado de deterioro de las instituciones, los iudicia populi comiencen a decaer (B. SANTALUCia, Derecho penal romano, traducción de Javier Paricio, Madrid, Ramón Areces, 1990, pp. 66-67).

${ }^{4}$ Se ha señalado el gran número de causas llevadas ante la cognitio popular, el prolongamiento excesivo de las mismas, la inoperancia que supone hacer frente a nuevas causas más complejas (B. SANTALUCiA, Derecho penal romano, op. cit., p. 70).

${ }^{5}$ Ibid. Giuffrè ha apuntado cómo el proceso comicial implicaba fuertes inconvenientes, entre los que destaca recoger solo los delitos más graves, marginando gran cantidad de ilícitos antisociales que son dejados al arbitrio incontrolado de la coercitio magistratual, o la duración del proceso, que hacía necesarias hasta cuatro reuniones comiciales por cada causa llevada ante los mismos (V. GiufFre, $I l$ «Diritto penale»..., op. cit., p. 36). Sobre esta cuestión vid. J. A. GonzÁlez Romanillos, Teoría y práctica judicial en época republicana, Madrid, Marcial Pons, 2016, pp. 19-55.

${ }^{6}$ B. Santalucia, Derecho penal romano, op. cit., p. 70. 
delito contra la seguridad del Estado. Sin embargo, dichas quaestiones terminarán estableciéndose como permanentes (quaestiones perpetuae), componiéndose de cónsules y pretores que estarán asistidos por un jurado a la hora de indagar y juzgar ${ }^{7}$.

\section{LA QUAESTIO MAMILIA, UNA CAUSA GENERAL POR DELITOS CONTRA EL ESTADO}

En este contexto, la quaestio Mamilia ${ }^{8}$ nace como una respuesta de las instituciones romanas a las acciones desleales que van perpetrando los nobles romanos en las diferentes misiones diplomáticas que acuden a Numidia. Parece acertado, creemos, ver en el motivo que lleva a crear este tribunal el intento de perseguir penalmente los delitos contra la seguridad del Estado, y, a nuestro juicio, existe una evidencia que permite decantarse con solvencia en tal sentido: sabemos que con anterioridad a la constitución de

7 Sobre el origen de las quaestiones perpetuae vid. J. A. GonZÁLEZ Romanillos, Aspectos procesales del crimen repetundarum de los orígenes a Sila, Madrid, Universidad Complutense de Madrid, 2003 pp. 17-55, e ÍD., «Antecedentes de la quaestio de repetundis», Iura: Rivista internazionale di Diritto romano e antico, núm. 54 (2006), pp. 136-55.

${ }^{8}$ En relación con la quaestio Mamilia han surgido discrepancias entre dos de los autores que más han estudiado acerca de este tribunal, Gruen y Badian. De esta forma, el primero asocia directamente la creación de la corte con la muerte de Cayo Graco en el 121 a. C., hecho que habría dado inicio a una verdadera lucha entre facciones dentro del propio Senado, siendo este el motivo del notable desprestigio de la institución. Defiende con ello que la quaestio Mamilia nacerá, más que por la preocupación hacia la integridad del Estado, fruto del odio existente entre las capas populares hacia la nobleza. Gruen encuentra totalmente secundario todo lo ocurrido en África y se centra en la venganza que provocase la muerte de Graco como acicate para dar pie a los procesos [E. S. GRUEN, Roman Politics and the Criminal Courts 149-78 b. C., Harvard, Harvard University Press, 1968, pp. 140 y 141-155, e ÍD., «The Lex Varia», The Journal of Roman Studies, vol. 55 (1965), pp. 59-73]. Ferrary defiende que, tras la legislación gracana del 123-122 a. C., que en materia de repetundis estableció jurados vetando a los senadores, surgió una nueva categoría de jueces ecuestres (indices Gracchani), que serían empleados de forma interesada para crear varias quaestiones temporales (extraordinariae), utilizadas para atacar al Senado. Aquí, la quaestio Mamilia sería un ejemplo. Afirma el autor francés que se habría optado por esta configuración de los tribunales en detrimento de los tradicionales iudicia populi, pues habiendo utilizado los últimos, en concreto en el 111 a. C., el tribuno C. Memio no logró encausar a quienes sí lo serían poco después a través de la quaestio Mamilia, pues uno de los tribunos había paralizado la causa utilizando su interccesio [J.-L. FERRARY, «Lois et procès de maiestate dans la Rome republicaine», en B. SANTALUCIA (ed.), La repressione criminale nella Roma republicana; fra norma e persuasione, Pavia, Cambridge University Press, 2009, p. 236]. En cuanto a Badian, este sí da importancia al tribunal, que se crea, dice, dentro de un marco excepcional para juzgar hechos concretos. Sin embargo, no cree que estemos ante un tribunal de alta traición en sentido estricto, idea que respalda con que, tras los procesos, la quaestio desaparece. 
la quaestio Mamilia, el tribuno Cayo Memio había intentado procesar a integrantes de las polémicas embajadas a África. De esta forma, en el 111 a. C. se abrirá juicio —un iudicium populi-9 ${ }^{9}$ por la misión del 117 a. C., y recoge Salustio como motivos concretos de los procesamientos:

«Haec atque alia buiuscemodi saepe in contiene dicendo Memmius populo persuadet, uti L. Cassius, qui tum praetor erat, ad Iugurtham mitteretur eumque interposita fides publica Roman diceret, quo facilius indicio regis Scauri et relicuorum, quos pecuniae captae arcessebat, delicta patefierent. Dum baec Romae geruntur, qui in Numidia relicti a Bestia exercitui praeerant, secuti morem imperatoris sui plurima et flagitiosissima facinora fecere. Fuere qui auro corrupti elephantos Iugurthae traderent, alii perfugas uendeuant, pars ex pacatis praedes agebant: tanta uis auaritiae in anims eorum ueluti tabes inuaserat» ${ }^{10}$.

Si acudimos al Digesto, en concreto al capítulo dedicado al delito de alta traición, Ulpiano afirma:

«Cuiusque dolo malo iureiurando quis adactus est, quo aduersus rem publicam faciat: cuinsque dolo malo exercitus populi romani in insidias deductus hostibusque proditus erit: factumque dolo malo cuius dicitur, quo minus hostes in potestatem populi Romani ueniat: cuiusque opera dolo malo bostes populi Romani commeatu armis telis equis pecunia aliaque qua re adiuti erunt: utque ex amicis hostes populi Romani fiant: cuiusque dolo malo factum erit, quo rex externae nationis populo Romano minus obtemperet: cuiusque opera dolo malo factum erit, quo magis obsides pecunia iumenta bostibus populi Romani dentur aduersus rem publicam» ${ }^{11}$.

Parece que las similitudes entre lo dispuesto en el Digesto y lo establecido siglos atrás en la quaestio Mamilia tienden a ser evidentes. Dicha quaestio incluye la acusación de haber entregado rehenes al enemigo (alii perfugas uendebant $)^{12}$, mientras que la obra justinianea dispone: quo magis

\footnotetext{
9 Sabemos que en este proceso llegó a comparecer en calidad de testigo el propio Yugurta. Sin embargo, el rey africano habría sobornado a uno de los tribunos, Cayo Bebio, que, una vez iniciado el juicio, mediante su intercessio habría evitado, no solo que Yugurta llegase a declarar, sino que la propia causa continuase [Sall., Ing., 33-34: «Baebium tribunum plebis magna mercede parat, cuius impudentia contra ius et iniurias omnis minutus foret [...] deinde ubi Memmius dicendi finem fecit et Ingurtha respondere iusus est, C. Baebius tribunus plebis, quem pecunia corruptum supra diximus, regem tecere iubet»].

${ }^{10}$ Sall., Ing., 31.

${ }_{11}^{11}$ D. 48.4.4.

12 Sall., Iug., 32.
} 
obsides pecunia iumenta hostibus populi Romani dentur aduersus rem publicam ${ }^{13}$. Al mismo tiempo, se acusa a los nobles romanos de entregar al enemigo lo que por entonces, y hasta hace poco tiempo, ha sido una temida arma de guerra, elefantes: fuere qui auro corrupti elephantos Ingurthae traderent ${ }^{14}$. El Digesto menciona igualmente la figura de un rey, advirtiendo que quien trabaje para hacer de este un enemigo de Roma, también será un traidor (quo rex exterae nationis populo Romano minus obtemperet) ${ }^{15}$. Pese a que Yugurta no es nombrado explícitamente, puestas todas las referencias en contexto, parece más que probable que el texto del Digesto se hubiese basado en lo acontecido en la quaestio Mamilia, y por ello podríamos ver a dicho tribunal especial como un importante hito dentro de la evolución que siguen los delito contra el Estado, esto es, los delitos de alta traición. Sin embargo, el proceso a uno de los reos mamilios, Espurio Postumio Albino, dentro de lo que fue la comisión de ilícitos sobre la comunidad, parece abrir una vía de conocimiento respecto a estos mismos delitos, cometidos ahora en el ámbito castrense. A nivel más general incluso, este juicio nos dará cuenta de un interesante cierto número de penas aplicables sobre los militares romanos.

\section{LOS PROCESOS MAMILIOS}

Las fuentes recogen hasta un total de cinco encausados en virtud de la quaestio Mamilia. Cicerón afirma:

«Nam inuidiosa lege [Mamilia quaestio] G. Galba sacerdotem et quattuor consularis. L. Bestiam C. Catonem Sp. Albinum ciuimque praestantissimum L. Opimium, Gracchi interfectorem, a populo absolutum, cum is contra populi studium stetisset, Gracchani iudices sustulerunt» ${ }^{16}$.

En cuanto a Gayo Sulpicio Galba, desconocemos el motivo concreto que llevó a su procesamiento, si bien es deducible por el contexto una acusación de soborno sobre su persona de parte de Yugurta. Sí pode-

${ }^{13}$ D. 48.4.4.

${ }^{14}$ Sall., Iug., 32. Sobre el elefante como arma de guerra en la Antigüedad vid. A. SÁnCHEz SANZ, «Los elefantes de guerra en los ejércitos de la Antigüedad», ArqueoUCA: Revista Digital Científica Independiente de Arqueología, núm. 1 (2011), pp. 51-56.

${ }^{15}$ D. 48.4.4.

16 Cic., Brut., 128. 
mos afirmar cómo su carrera se fue al traste tras ser juzgado, pues su connivencia (coniurationis) con el monarca africano le valió del desprecio de todos ${ }^{17}$.

Lucio Opimio, que había presidido la embajada senatorial del 117 a. C., es otro de los reos, cayendo finalmente de forma ignominiosa ${ }^{18}$, corrompido con el dinero recibido de manos enemigas, motivo por el cual acabará en el exilio ${ }^{19}$.

Lucio Calpurnio Bestia, cónsul en el 111 a. C., quien lograse un acuerdo de paz con los númidas durante su cargo, no pareció haber recibido para ello la preceptiva aprobación del Senado y el pueblo de Roma -obligada e inexcusable para estos asuntos - ${ }^{20}$. Como consecuencia Calpurnio fue acusado igualmente de haber recibido sobornos del monarca y, además, su polémico acuerdo de paz no fue ratificado ${ }^{21}$.

Poco sabemos de otro de los encausados, Cayo Porcio Catón. Apenas lo recogido por Cicerón ${ }^{22}$, que en otro pasaje parece hacernos ver que el reo terminaría siendo condenado, por lo que habría marchado al exilio, pues el orador pone a Catón como ejemplo de la incompatibilidad de tener doble ciudadanía para un romano ${ }^{23}$, lo que hace factible la existencia de una ciudad de acogida para Catón con el subsiguiente estreno de nueva ciudadanía para el $\mathrm{reo}^{24}$.

${ }^{17}$ Ibid.: «[...] nam rogatio Mamilia, Iugurtbinae coniurationis inuidia».

${ }^{18}$ Cic., Sest., 140: «[...] indignissime concidit».

19 Plut., Gr., 18.1.

${ }^{20}$ Liv., Per., 64: «idque Calpurnius Bestia cos. Gerere iussus pacem cum Ingurta iniussu populi et senatus fecit».

${ }^{21}$ Eutr., 4.26: «Missus aduersus eum consul Calpurnius Bestia, corruptus regis pecunia, pacem cum eo flagitiosissimam fecit, quae a senatu improbata est».

${ }^{22}$ Cic., Brut., 128: «[...] C. Catonem [...]».

${ }^{23}$ Cic., Balb., 28: «Neque solum dicatione, quod in calamitate clarissimis uiris Q. Maximo. C. Laerati, Q. Philippo Nuceriae, C. Catoni Tarracone, Q. Caepioni, P. Rutilio Zmyrnae uidimus acudisse, ut earum cinitatum fierent ciues».

${ }^{24}$ El ius exilii no es de aplicación automática tras ser el reo condenado. La condena, tal como ocurriera en el caso de Catón, ha de ser a muerte para que podamos hablar del exilio, pues solo se ejecutará al condenado si este no decide exiliarse. Por ello, hemos de entender que el ius exilii es meramente opcional. Del mismo modo, si un romano condenado a pena capital decidía acogerse a dicha opción, este acabaría perdiendo su ciudadanía romana, pero no de forma automática, sino tras acogerse a otra ciudadanía en su punto de destino. Nos lo explica muy bien CiCERÓN (de dom., 30.78): "Quim etiam si decemuiri sacramentum in libertatem iniustum iudicassent, tamen, quotienscumque uellet quis, boc in genere solo rem iudicatam referri posse uoluerunt; ciuitatem uero nemo umquam ullo populi iussu amitter inuitus. Qui ciues Romani in colonias latinas proficiscebantur fieri non poterant Latini, nisi erant auctores facti nomenque dederant: qui erant rerum capitalium condemnati non prius hanc ciuitatem amittebant quam erant in eam recepti, quo uertendi, hoc est mutandi, soli causa uenerant. Id autem ut esset facundum, non ademptione ciuitatis sed tect $i$ 
El juicio a Espurio Postumio Albino es, con notable diferencia, del que más información disponemos en las fuentes gracias, sobre todo, a Salustio. Sin embargo, no es en lo extenso del relato donde apreciamos el mayor interés, sino en los delitos que, en el ámbito militar, cometerá el reo, y estos son extensamente narrados. Es, por otra parte, igualmente llamativo comprobar cómo será el hermano de Espurio, Aulo Postumio Albino, quien, siguiendo la senda de su hermano como nefasto militar, acabe provocando que se abra un proceso contra el primero.

Espurio había sido nombrado junto a Marco Minucio Rufo cónsul en el 110 a. C., si bien un año antes ya se le había encomendado la dirección de las operaciones militares en Numidia. En el 109 a. C. viaja a África, y lo hace decidido a terminar la guerra cuanto antes, para lo cual porta consigo importantes recursos monetarios y militares. El romano tiene interés en tornar a Roma con prontitud ${ }^{25}$. Pero ya en Numidia, Yugurta parece percatarse de las «prisas» con que llega el romano y, de inmediato, el monarca da paso a una actitud bélica ambigua, sugiriendo unas veces su inminente rendición, y otras, lo contrario ${ }^{26}$. Ante tal situación, Salustio afirma que Escauro es perfecto conocedor del doble juego del rey, pero no solo eso, sino que cree que, si la guerra no llegó entonces a su fin, ello se debió a un fraude. Y aquí, dicho fraude no se puede entender de otra forma que como un soborno de parte del enemigo:

«Ac fuere qui tum Albinum haud ignarum consili regis existimarent neque ex tanta properantia tan facile tractum bellum socordia magis quam dolo crederent ${ }^{27}$.

et aquae et ignis interdictio ne facienbant». También con relación a la pérdida de ciudadanía aparejada al ius exilii (Cic., Caec., 34.100). Por tanto, la ciudadanía romana no se pierde por el exilio, sino cuando el reo se hace ciudadano en otro punto. Pero no cualquier ciudad servirá, sino solo aquellas con las que Roma tenga firmado un convenio al respecto (ibid., 30.98): «Certe quaeri hoc solere me non praeterit ut ex me ea quae tibi in mentem non ueniunt audias, quem ad modum, si ciuitas adimi non possit, in colonias Latinas saepe nostri ciues profecti sint. Aut sua uoluntate aut legis multa profecti sunt. Quam multam si sufferre uoluissent tum manere in ciuitate potuissent». Para saber más vid. T. Mommsen, El Derecho penal romano, traducción de P. Dorado, Madrid, Analecta, 1905, p. 597; A. MagdeLAIN, «Ricerche sull'exilium nel periodo republicano», SDHI, vol. 28 (1961), pp. 426 y ss., y M. Torres Aguilar, «La pena del exilio: sus orígenes en el Derecho romano», AHDE, núm. 63-64 (1993-1994), p. 712, entre otros.

${ }_{25}$ Sall., Iug., 7: «Interim Albinus renouato bello commeatum, stipendium aliaque, quae militibus usui forent, maturat in Africam portare; ac statim ipse profectus, uti ante comitia, quod tempus baud longe aberat. Armis aut deditione aut quouis modo bellu conficeret»s.

${ }^{26}$ Ibid., 36.2: «At contra Iugurtha trahere omnia et alias deinde alias morae causas facere».

${ }^{27}$ Ibid., 36.3. 
Un hecho parece contribuir a la idea de posible fraude en la fulgurante campaña militar; hablamos de la impaciencia con que Espurio decide volver a Roma para presentarse al consulado. Y si ello en sí termina resultando un error fatal, peores consecuencias se sucederán de la decisión que toma dejando el mando de la guerra que, si bien continuará, lo hará comandada por su hermano Aulo con el cargo de propretor. A todo ello habrá de sumarse que llegado Espurio a Roma su presencia en la ciudad tornará a prolongarse excesivamente. Todo por la voluntad de un grupo de tribunos, en concreto dos, Publio Lúculo y Lucio Anio, que se resisten a abandonar sus cargos en contra del criterio de sus colegas ${ }^{28}$. La ralentización de los asuntos en Roma dará un notable margen a Yugurta en África, sobre todo cuando se percate de la ineptitud militar y codicia que porta el hermano de Escauro.

\section{ACCIONES MILITARES DE AULO POSTUMIO ALBINO}

Siguiendo los pasos de su hermano, Aulo iniciará hostilidades con demasiada premura por liquidar la contienda cuanto antes, buscando con ello, ante todo, el lucro y la gloria personal ${ }^{29}$. El romano muestra así su temor ante una inminente vuelta de su hermano que, inmerso en sus propios problemas en Roma, le estaba ofreciendo un tiempo precioso.

Los romanos inician el asedio a la ciudad de Suthul, plaza en la que, se sabía, estaba depositado el tesoro del reino africano ${ }^{30}$, e inmediatamente tiene oportunidad Yugurta de ver reflejadas e intensificadas las debilidades de Escauro en su hermano Aulo, algo que convertirá al romano en vulnerable en el campo de batalla ante un rey tan astuto ${ }^{31}$. Pese a que los africanos acaben alejando a los romanos de tan importante plaza por medio de una maniobra de distracción, no podemos ver aún por parte romana acciones contrarias a su código militar; Aulo ha intentado tomar un gran botín al enemigo y, descontando su previsible lucro personal, es evidente que, de

${ }^{28}$ Ibid., 37.1-2: «Ea tempestate Romae seditionibus tribuniciis atrociter res publica agitabatur P. Lucullus et L. Annius tribuni plebis resistentibus collegis continuare magistratum nitebantur, quae dissensio totius anni comitia impediebat».

${ }^{29}$ Ibid., 37.3: «[...] aut conficiundi belli aut terrore exrcitus ab rege pecuniae capiundae».

30 Oros., 5.15.6 (habla de Calama y no de Suthul): «[...] apud Calaman urbem thesauris regiis conditis inhiantem bello oppessit adque uicto ignominiosissimum foedus exegit»; Sall., Iug., 37.3: «oppidum Suthul, ubi regis thesauri erant».

${ }^{31}$ Sall., Iug., 38.2: «Denique Aulum spe pactionis perpulit, uti relicto Sutbule in abditas regiones sese ueluti cedentem insequeretur». 
haberlo logrado, perder tal suma de riqueza hubiese supuesto asestar un duro golpe a las finanzas del enemigo. Igualmente, ello habría significado la repartición de riqueza entre la propia tropa romana, el mejor de los combustibles para lograr de estos una lucha más enérgica y mayor «motivación.» No obstante, parece que la forma en que se materializó el asedio no resultó la más apropiada, pues los terrenos aledaños a Suthul estaban empantanados. Con todo, la precipitación de Aulo se vio a ojos del enemigo como señal de codicia, torpeza e inferioridad en combate ${ }^{32}$. Yugurta comienza entonces a jugar tácticamente en campaña con los romanos: estos acaban abandonando el asedio en abierta persecución del enemigo sin saber que, en realidad, este les está haciendo penetrar en el país fingiendo huir en desbandada. Los romanos estaban, en definitiva, cayendo en una emboscada.

Dan comienzo entonces las calamidades en el ejército romano: para que los planes de Yugurta surtan efecto, el africano manda contactar con un grupo de entre las propias fuerzas romanas, a las que acaba pudiendo sobornar para que le faciliten la ejecución del ataque final sobre la fuerza itálica. Los númidas buscaban ocupar el campamento enemigo, y para ello necesitaban la colaboración desde su interior, esto es, necesitaban la presencia de traidores entre las filas romanas. El plan implicaba rodear el asentamiento en la noche, y con ello - algo que no deja de sorprender, estando frente a un ejército compuesto por nada menos que cuarenta mil hombres- ${ }^{33}$ se consiguió que reinase el caos dentro del campamento ${ }^{34}$. El papel de los traidores era ahora clave, pero ¿de quiénes hablamos? En su mayoría, de un importante número de miembros de las fuerzas auxiliares, pero también un pequeño grupo de legionarios y, más llamativo aún, una figura destacada y vertebradora dentro del ejército como lo es un centurión, en concreto el primero de la legión tercera. Este individuo será clave para que el enemigo pueda entrar en masa por un punto concreto de la empalizada del campamento a él asignada; hará pasar a los intrusos por el parapeto cuya custodia tenía encomendada ${ }^{35}$. Al amanecer el campamento había caído.

32 Ibid., 37.4: «Quod quamquam et saenitia temporis et opportunitate loci neque capi neque obsideri pterant —nam circum murum situm in praerupti montis extremo planities limosa biemalibus aquis paludem fecerat-, tamen aut simulandi gratia, quo regi formidinem adderet, aut cupidine caecus ob tesauros oppidi potiendi nineas agere, aggerem iacere aliaque, quae incepto usui forent, properare».

${ }^{33}$ Oros., 5.15.6: «[...] que mis quadraginta milium armatorum exercitui praefecerat».

34 Sall., Iug., 38.5: «Milites romani, perculsi tumultu insolito, arma capere alii, se abdere fugere, pars territorios conformare, trepidare omnibus locis».

35 Ibid., 38.6: «Sed ex eo numero, quos paulo ante corruptos diximus, cohors una Ligurum 
La clave del fulgurante éxito enemigo había residido en su insistente labor tanteando («temptabat») al mayor número de romanos — mandos y soldados por igual - para que estos, o bien desertasen, o bien abandonasen sus puestos de guardia en el momento del ataque:

«Interea per homines callidos diu noctuque exercitum temptabat centuriones ducesque tumarum partim uti transfugerent corrumpere, alii signo dato locum uti desererent ${ }^{36}$.

Respecto a la existencia de tránsfugas y traidores dentro del ejército, el Derecho romano era claro e implacable, tal y como nos lo recuerda Tarrunteno Paterno:

«Proditores, transfugae plerumque capite puniuntur, et exauctorati torquentur; nam pro hoste, non pro milite habentur» ${ }^{37}$.

Los traidores o desertores son, en tiempo de guerra, ejecutados sumariamente con tormento tras perder su condición de militares mediante la degradación automática de su ciudadanía. Lo acontecido era de gravedad; la fuga de tropa auxiliar (soldados tracios) ${ }^{38}$, siendo en sí un hecho doloso, podría generar menor impacto, pues hablamos de no romanos, individuos no ciudadanos a los que se podrá presuponer una menor raigambre con la tropa romana y con la metrópoli en general. Es por ello que estas fuerzas sí pueden ser más susceptibles de pasarse al bando enemigo. Sin embargo, la traición de los propios soldados romanos (paucis gregariis militibus) supone un hecho de mayor gravedad. Y la pena por tan vil acción no ha de ser otra que la muerte, pues hablamos de soldados que por voluntad propia deciden pasar a formar parte de las fuerzas enemigas. En relación con esto, Modestino recuerda, sin necesidad de llegar a este caso extremo, y ofreciendo el supuesto de militares que decidan fugarse y, tras ello, refugiarse en las filas enemigas, cómo la ley debe condenar a muerte a tales individuos con tormento (llevados a las fieras o a la horca):

cum duabus turmis Thracum et paucis gregariis militibus transiere ad regem, et centurio primi pili tertiae legionis per munitionem, quam uti defenderet acceperat, locum hostibus introeundi dedit, eaque Numidiae cuncti irrupere».

${ }^{36}$ Ibid., 38.3-4.

37 D. 49.16 .7$.

${ }^{38}$ Sall., Iug., 38.6: «[...] turmis Thracium». 
«Is, qui ad bostem confugit et rediit, torquebitur, ad bestiasque uel in furcam damnabitur, quamuis milites nibil eorum patientur» ${ }^{39}$.

Conviene en este punto aclarar cómo de ordinario, en situación de paz, el código militar tiende a desarrollar mayor permisividad en gran cantidad de los ilícitos susceptibles de ser cometidos por un soldado en ejercicio. De este modo, las multas, la deposición de cargos, el cambio de milicia o el licenciamiento, tienden a constituir, por norma, los castigos previstos para los soldados ${ }^{40}$. Los legionarios no serán sometidos bajo ningún concepto a penas que impliquen trabajos forzosos - se habla en concreto de las minas-, ni mucho menos serán torturados (nam in metallum, aut in opus metalli non dauntur, nec torquentur). Pero todo ello será aplicable solo en tiempo de paz, y es por esto por lo que, como comentamos, en estado de guerra la gran mayoría de graves infracciones presentes en el código militar romano conllevarán una inmediata aplicación de la pena capital. Adriano Menandro escribe al respecto:

«Qui in pace deseruit, eques gradu pellendus est, pedes militiam mutat, in bello idem admissum capite puniendum est» ${ }^{41}$.

Podríamos señalar lo incoherente que resultaría ejecutar a un soldado romano, que tiene, lógicamente, ciudadanía romana, cuando sabemos cómo desde antiguo, en torno al 300 a. C., y en virtud de la lex Porcia, se había establecido que, en adelante, ningún ciudadano romano pudiese ser torturado ${ }^{42}$. Es aquí cuando hemos de advertir que, pese a ser la ejecución fruto de un juicio sumarísimo, antes de ello dará tiempo a degradar al reo de su condición de soldado, pudiendo estar aquí ante la práctica de una capitis deminutio maxima, la cual implica la pérdida automática de la ciudadanía romana, hecho que haría más coherente poder aplicar la tortura sin contravenir la legislación Porcia.

La fuga de un militar romano durante el combate, ya sea un soldado raso o un mando - si acaso resulta más grave en el segundo supuestoestá igualmente penada por el Derecho romano, concretándose en nues-

39 D. 49.16.3.10.

${ }^{40}$ D. 49.16.3.1: «Poenae militum buiuscemodi sunt: castigatio, pecuniaria mulcta, munerum indicto militae mutatio, gradus deiectio, ignominiosa misio».

${ }^{41}$ D. 49.16.5.

42 Del contenido de la lex Porcia nos habla Cicerón (Rab. perd., 4.12): «Porcia lex uirgas ab omnium ciuium Romanorum corpore amouit, hic misericors flagella rettulit». 
tro caso ambas posibilidades. Con relación a la tropa que abandona la protección de una parte de las empalizadas del campamento, es interesante lo contenido al respecto en el Digesto: qui a fossato recedit capite puniendus est ${ }^{43}$, y en cuanto a los mandos: qui stationis minus relinquit, plus quam emansor est ${ }^{44}$. En concreto, Salustio señala como clave la figura de un centurión que dejará el paso abierto al enemigo.

Hemos apuntado lo importante que llega a erigirse a nivel estratégico la figura del centurión en el ejército romano, hasta el punto de estar este plenamente protegido por la normativa militar en el pleno ejercicio de sus funciones. De esta manera, llegó a contemplarse que quien rompiese la vara de castigo del centurión - todo un símbolo de su mando- sería condenado a muerte ${ }^{45}$. Se comprende fácilmente que la defección de tal mando frente a los númidas otorga un cariz más dramático si cabe a los hechos.

Como corolario a las insistentes violaciones del código militar romano sabemos que, cuando ya todo el campamento romano se había dado a la fuga, dejó abandonadas gran parte de sus armas (plerique abiectis armis) para mayor deshonra, dado que ello estaba totalmente prohibido, siendo castigado con pena capital: miles, qui in bello arma amisit, uel alienauit, capite punitur ${ }^{46}$.

Aulo había dejado caer el campamento y, pese a que la traición de parte de mandos y tropa resultara determinante, él era el responsable máximo de aquella fuerza en ausencia de su hermano, y la norma militar reconocerá esa situación concreta un siglo más tarde y la catalogará como un delito por alta traición a través de la lex Iulia de maiestate: «lex autem Iulia maiestatis praecipit eum, qui maiestatem publicam laesarit, teneri: qualis est ille, qui in bellis cesserit aut arcem tenuerit aut castra concesserit» ${ }^{47}$.

\section{RENDICIÓN DE AULO. HUMILLACIÓN SUB IUGUM Y PAZ ILEGAL}

Ocupado el campamento y sometido gran parte del ejército romano, Yugurta se ve con autoridad suficiente para dar el siguiente paso; decide

${ }^{43}$ D. 49.16.3.4.

${ }^{44}$ Hablamos de emansor cuando nos referimos al soldado que deserta, pero con el tiempo acaba volviendo por su propia voluntad al campamento. En tiempo de paz este hecho no llevará aparejada la pena capital; en situación de guerra, sí.

${ }^{45}$ D. 49.16.13.4: «si ex industria fregit, uel manum centurioni intulit, capite punitur».

${ }^{46}$ D. 49.16 .3 .13 .

${ }^{47}$ D. 48.4.3. 
proponer la paz a la fuerza extranjera, si bien bajo una doble condición, que el ejército romano salga de África en un máximo de diez días ${ }^{48}$ y, peor aún, que todo él pase sub iugum ${ }^{49}$. Esto último supone un ritual que, en origen, tenía un carácter purificatorio, tal y como nos cuenta Livio, que relatando el proceso a Horacio recoge cómo el rey quiso limpiar la culpa del reo - este había matado a su hermana por llorar al enemigo- haciéndolo pasar por un arco especial («transmisso per niam tigillo, capite adoperto uelut sub ingum misit inuenem») ${ }^{50}$. Pasado el tiempo, dicha función - con un claro componente sacro- irá degenerando en otra en que acabará prevaleciendo el objetivo de humillar a los vencidos en combate.

Idéntica situación a la de Numidia vivieron los romanos en el 458 a. C. ${ }^{51}$, si bien esta vez serán ellos quienes obliguen al enemigo — los ecuos- a pasar bajo el yugo: «[...] sed ut exprimatur tandem confessio subactam dominamque ese gentem, sub iugum abituros» ${ }^{52}$.

El otro hecho grave, el acuerdo de paz, aunque impuesto por Yugurta, no competía a Aulo resolverlo favorablemente, pues para ello requería de la autorización del pueblo y el Senado de Roma, costumbre establecida desde tiempo inmemorial. No es así de extrañar que, al llegar la noticia de la humillante derrota al Lacio, el Senado advirtiese de inmediato a Espurio, hermano de Aulo, de la total invalidez de los acuerdos adoptados por su hermano: «Senatus ita uti par fuerat decernit suo atque populi iniussu nullum potuisse foedus fieri» ${ }^{53}$.

Sabemos que, por ejemplo, Aulo Gabinio había estado ejerciendo de gobernador en Siria y durante su estancia abandonó la provincia asignada para reponer en el trono a Ptolomeo, generando ello una guerra en Egipto en la que el romano y su ejército se implicaron abiertamente. Por esto, Gabinio será juzgado en Roma en el 54 a. C. por un tribunal de alta traición (quaestio de maiestate), y entre otros cargos, se acusará al exgober-

${ }^{48}$ Sall., Iug., 38.9: «uti diebus decem Numidia decederet».

${ }^{49}$ Ibid. Vid. I. M. VAzov y E. Gosse, Under the yoke; a romance of Bulgarian liberty, London, W. Heinemann, 1912.

${ }^{50}$ Liv., 1.26.

${ }^{51}$ Bajo la dictadura de Quincio Cincinato.

52 Ibid., 3.28. Otros escenarios bélicos son ejemplo de la fuerte humillación que suponía para un ejército derrotado pasar sub ingum. Ocurrirá, por ejemplo, tras la célebre derrota romana en la batalla de las Horcas Caudinas (321 a. C.), Liv., 9.6: «Primi consules prope seminudi sub ingum missi; tum ut quisque gradu proximus erat, ita ignominiae obiectus; tum deinceps singulae legiones». Marco Atilio, tras derrotar a los samnitas, también les aplicó dicha humillación (ibid., 10.36): «Captiuorum numerus fuit septem milium octingentorum, qui omnes nudi sub iugum missi».

53 Sall., Iug., 39.3. 
nador de haber iniciado una guerra sin el consentimiento del Senado y el pueblo romanos ${ }^{54}$. En el caso de Aulo, este no inició la guerra, sino que firmó su fin de forma unilateral, y, como vemos, tanto en un caso como en el otro no era legal acometerlo sin la preceptiva venia de las instituciones de Roma.

\section{ESPURIO VUELVE A ÁFRICA}

La noticia del fracaso de Aulo causó honda indignación en Italia y, por encima de cuanto había ocurrido en el campo de batalla, se entendió que el nefasto romano había mancillado con sus deshonrosas acciones la gloria imperi de Roma ${ }^{55}$. Espurio había dejado a su hermano de forma provisional a cargo del polvorín númida, pero en último término era responsable de todo cuanto pasase allí, por lo que partió de inmediato a África con refuerzos. Lo que encontró a su llegada fue desolador. El ejército de Aulo - que, por cierto, no había abandonado finalmente el reino de Yugurta en contra de lo acordado- se había instalado en una completa anarquía:

«Sed ubi in Africam uenit exercitus ei traditur a Sp. Albano proconsule iners, in bellis, neque periculi neque laboris patiens, lingua quam manu promtior, praedator ex sociis et ipse praeda hostium, sine imperio et modestia habitus» ${ }^{56}$.

El texto muestra dos aspectos que a nuestro parecer presentan igual importancia. Por un lado, el ejército vivía una indisciplina total, pero, por otro, se afirma que además se estaba dedicando a acosar pueblos amigos de Roma, a aliados (socii). Ambas situaciones se ven reflejadas con severo castigo en la legislación romana. Tal es así que, si nos detenemos en la provocación a los enemigos — debemos entender por estos no a los númidas, sino a otros posibles pueblos vecinos que mantienen por entonces una relación pacífica con Roma- parece que los soldados romanos, alejados del enemigo, se habían instalado en un punto permanente desde donde acosaban y saqueaban a otros pueblos: ello supone nada menos que turbar la paz con quienes no están levantados en armas contra los romanos.

${ }^{54}$ Cass. Dio., 39.56.4. Sobre esta cuestión vid. J. A. GonzÁlez Romanillos, La corrupción política en época de Julio César, Granada, Comares, 2009, pp. 73-75.

55 Sall., Iug., 39.1.

${ }^{56}$ Ibid., 44.1-2. 
$Y$ en el Digesto se advierte claramente que aquel militar que con sus acciones perturbe la paz será condenado a muerte («milites turbator pacis capite punitur») $)^{57}$.

En las fuentes romanas encontramos algunos casos donde se ve reflejada la censura a las actitudes hostiles con pueblos amigos de Roma, apareciendo en concreto uno significativo. En el proceso a Verres, unos años posterior (75-70 a. C.), Cicerón, actuando como abogado acusador de aquel bajo la conocida acusación de repetundis ${ }^{58}$ por el expolio que llevó a cabo durante su mandato como propretor en Sicilia, pese a no ser el delito de alta traición (maiestas) el principal de esta causa, sostuvo cómo Verres habría de comparecer también ante una quaestio de maiestate por diferentes ilícitos, siendo uno de ellos el que sigue: los hijos del rey Antíoco, aliado de Roma, en calidad de príncipes de Siria hicieron una visita a la ciudad del Lacio como invitados, y ya de vuelta a Oriente, ejerciendo de propretor Verres en Sicilia, este decide acogerlos y agasajarlos unos días en la isla en calidad de huéspedes. Cuando los príncipes deciden retomar el viaje, el propretor se incauta del rico ajuar que portaban para gran disgusto de los aristócratas orientales, quienes terminan siendo expulsados de la isla.

Cicerón informa al Senado que dicho robo a punto había estado de arruinar la fama y el prestigio del pueblo romano, llegando incluso - $y$ esto es lo más grave- a expoliar y traicionar la hospitalidad a reyes amigos de Roma, provocando la enemistad de estos ${ }^{59}$. He aquí un ejemplo de cómo la justicia romana perseguía las provocaciones a los aliados, algo del todo razonable, pues tales actos implicaban poner en peligro, innecesaria y temerariamente, a un fuerte contingente militar que en este caso huye del enemigo pero, en cambio, ataca decididamente a los aliados. No iba por ello Cicerón muy desencaminado en la acusación de maiestas, pues como resalta Ulpiano, esta aparece como delito «[...] uel aduersus securitatem eius committitur» ${ }^{60}$. Y en el caso que nos ocupa es un ejér-

57 D. 49.16.16. Las XII Tablas (tab. 8.5) ya habían dispuesto la ejecución del romano que provocase al enemigo: «[...] qui hostem concitauerit $[$...] capite puniri». Debemos entender dicha norma en un escenario de no hostilidad entre las partes, y donde tal acción, provocadora, pondría en peligro la paz, siendo todo acto violento llevado a cabo, ya sea contra un enemigo, o contra un aliado, en último término de consecuencias negativas para toda la comunidad romana.

${ }^{58}$ La causa se lleva ante una quaestio de repetundis.

59 Cic., Verr., 4.60: «[...] existimatio atque auctoritas nominis populi Romani imminuta [...] bospitium spoliatum ac proditum, abalienti scelere, istius a nobis omnes reges amicissimi, nationesque quae in eorum regno ac dicione sunt».

${ }^{60}$ D. 48.4.11. 
cito derrotado y humillado el que pone, una vez más, al mundo romano en claro peligro.

El otro gran problema que encuentra Espurio a su llegada, la fuerte indisciplina, constituye un factor de aniquilación que puede conducir a la autodestrucción de cualquier ejército en todo tiempo y lugar. Pero el romano, una vez más, se ve incapaz de enderezar el rumbo de las cosas. En Roma no se pierde el tiempo y, tras destituir a Espurio, se decide enviar otro mando militar, Quinto Cecilio Metelo, que tras pisar suelo africano decidirá postergar las acciones bélicas y dar prioridad a la recomposición de un ejército que era ya ingobernable.

$\mathrm{La}$ indisciplina castrense, muy presente en el Derecho romano, será vista siempre como un delito importante: «omne delictum est militis, quod aliter, quam disciplina communis exigit, committitur, ueluti segnitiae crimen, uel contumaciae, uel desidiae» ${ }^{61}$. Estos tres horrendos calificativos se ven perfectamente ejemplificados en el ejército romano de África. Pero ¿quién es el responsable último del nivel de disciplina en el ejército? Naturalmente, su máximo mando ${ }^{62}$.

Si la norma no permitía a los soldados llevar a cabo actividades privadas ajenas al ámbito militar («ad opus priuatum, piscatum, uonatum militem non mittere») $)^{63}$, la tropa de África no solo contravenía esto, sino que además dichas actividades eran llevadas al plano delictivo: «lixae permixti cum militibus diu noctuque uagabantur; et palantes agros uastare, uillas expugnarte pecoris» ${ }^{64}$. Aulo había relajado a la tropa hasta tal extremo que, lejos de seguir una rutina de ejercicios de adiestramiento o cambiar la ubicación del campamento con relativa frecuencia, el contingente solo se movía cuando el fuerte hedor así lo obligaba, pues se tendía a mantener los soldados en una actitud sedentaria e insalubre ${ }^{65}$. Vegetio, autor del Epitoma institutorum rei militaris -importante fuente para el estudio del mundo militar romano- recoge que para mantener la disciplina en el campamento es fundamental el continuo entrenamiento de la tropa ${ }^{66}$.

La indisciplina no era el único mal, pues otra situación ponía más directamente en peligro la integridad física de las personas y bienes del

${ }^{61}$ D. 49.16.6.

${ }^{62}$ D. 49.16.12: «[...] sed etiam in obseruanda disciplina consistit».

${ }^{63}$ D. 49.16.12.1.

${ }^{64}$ Sall., Iug., 44.5.

${ }^{65}$ Ibid., 44.4: «plerumque milites statiuis castris habebat, nisi cum odor aut pabuli egestas locum mutare subegerat».

${ }^{66}$ Veget., 1.1: «Nulla enim alia re uidemus populum Romanum orbem subegisse terrarum nisi armorum exercitio, disciplina castrorum usuque militiae». 
campamento frente a una acción enemiga: ese insalubre campamento, que tendía a ser permanente, ni fue fortificado, ni tan siquiera se dotó de vigías en sus inmediaciones. Este hecho, muy delicado, compromete la seguridad de todos, pues hablamos de la inexistencia de perímetro defensivo alguno, ni tan siquiera de unos centinelas que alertando puedan dar tiempo en un ataque nocturno para que los legionarios al menos empuñen un arma con el que defenderse en un cuerpo a cuerpo. Así todo, parece que el enemigo no estaba acechando directamente a la tropa de Aulo, la cual, tras la firma del tratado de paz, e incumpliendo el plazo de diez días para salir del reino, se quedó en alguna zona de este menos comprometida y expuesta a los númidas. De otro modo no se entiende tal desidia e incluso que la propia tropa se dedicase al bandolerismo por la zona.

Es importante llegar a la conclusión de que, si bien pudo existir una amenaza del enemigo, esta pudo no ser directa, pues hemos de saber que, según se dé o no la mayor o menor cercanía de este, la disposición que prevé el reglamento romano para las fortificaciones del campamento cambiará. Si los hombres de Yugurta no parecían estar muy cerca, Aulo no tenía mayor problema para desarrollar su esquema defensivo, pues cuenta Vegetio que en ese caso no existe mucha dificultad para fortificar un campamento, no estando el enemigo a la vista: no serán necesarias aquí las fuertes empalizadas que sí aparecen en cambio cuando el enemigo ofrece una amenaza directa, sino que bastará con la construcción de una estrecha zanja que rodee el perímetro del campamento, y ella se acompañará en su parte exterior de diferentes obstáculos colocados estratégicamente para entorpecer una posible incursión enemiga ${ }^{67}$.

Aulo no habría tenido la necesidad de construir empalizadas, pero sí un foso, algo que no debió hacer, y cuando Salustio dice que no fortificó el campamento, debemos entenderlo asociado a la no construcción de un foso circundante. Queda atestiguada igualmente la no presencia de los centinelas, elemento del todo habitual en el campamento y fundamental para mantenerlo alerta. Tal es así que entre las principales labores de los máximos responsables de una plaza militar se incluía la inspección personal y periódica de los diferentes puestos de guardia repartidos por la fortificación (uigilias interdum circumire) ${ }^{68}$. Resultaba tan importante establecer, mantener y defender un perímetro de seguridad en torno al

${ }^{67}$ Ibid., 1.24: «Nam si nimia necesitas non premit, caespites circumciduntur e terra et ex his uelut murus instruitur, altus pedibus supra terram, ita ut in ante sit fossa, de que leuati sunt caespites; deinde tumultuaria fossa fit lata pedes nouem et alta pedes VII».

${ }^{68}$ D. 49.16-12.2. 
campamento que estaba establecido para quien lo violase penetrando en el interior su ajusticiamiento de forma inmediata:

«Nec non et si uallum quis transscendat, aut per murum castra ingrediatur, capite punitur» ${ }^{69}$.

Dicho esto, es probable también que lo más conveniente para un campamento que tendía a ser peligrosamente estático en su localización, fuese la construcción de una estructura empalizada. En todo caso, las medidas de protección para tan gran ejército en terreno enemigo tendieron a ser más que temerarias, y ello sospechando que pudieron ser incluso inexistentes. Tal situación acercaba a Aulo primero, por haber iniciado tal práctica, y a Espurio después, por no haber sabido revertir el problema a su regreso, a una situación muy comprometida con la justicia romana, pues los hechos eran perfectamente encuadrables penalmente dentro del código militar romano. Sin embargo, quien será juzgado por la quaestio Mamilia será Espurio, o ello es al menos lo que podemos deducir de las fuentes, que en ningún momento hablan de Aulo como procesado. Probablemente se entendió que Espurio era responsable último de todo lo acontecido, siendo él quien viaja a África a hacer la guerra en origen, y siendo igualmente él quien decide abandonar luego el campo de batalla. Es él también quien vuelve apresuradamente in extremis para tratar de reconducir lo que era ya todo un desastre militar.

\section{LOS EXCESOS EN ÁFRICA Y LA SEGURIDAD DEL ESTADO}

La constitución de la quaestio Mamilia supone un hito fundamental en el desarrollo penal de los delitos contra el Estado en Roma, y dentro de tal tribunal las acusaciones contra Espurio serán el detonante que lleve a procesar a todos los implicados en las corrompidas embajadas romanas enviadas a Numidia. Además, conociendo que tanto Espurio como su hermano Aulo en calidad de altos mandos del ejército romano incumplieron gravemente diversas normas del código militar romano, resulta interesante comprobar cómo ese conjunto de delitos cometidos, siendo de diferente índole —si bien siempre dentro del ámbito castrense—fueron unidos en Roma

${ }^{69}$ D. 49.16.2.17. 
bajo un nexo común: todos ellos dañaban la imagen y el prestigio de Roma en el exterior, y ello ponía en peligro su seguridad, pues desde hacía tiempo los romanos habían apostado su futuro a una empresa de expansionismo militar por todo el Mediterráneo. De ahí que Salustio refiera cómo desde Roma se veía el caos militar de África como un ataque a la gloria imperi de la ciudad del Lacio.

Encontrándose Espurio en Roma para presentarse al consulado había llegado la noticia de la humillante derrota de su hermano, y dice Salustio que ello se vio como una dolorosa herida a la gloria del imperio ( «pars dolere pro gloria imperi» $)^{70}$. Se había manchado la imagen de Roma, y podríamos ver en la «gloria imperi» el embrión de lo que luego será la maiestas como término de exaltación, superioridad y respeto al poder romano sobre el resto de pueblos. En el caso de Espurio y Aulo se entendió que las acciones de ambos iban en detrimento del interés general romano, pero por entonces está aún por construir el concepto jurídico y todavía no se ha dado un nombre definitivo — será finalmente la referida maiestas — ${ }^{71}$ al bien protegible.

Espurio y Aulo no solo habían puesto en peligro la integridad de todo un gran ejército romano, sino que, más grave aún, con ello ponían en serio riesgo la propia seguridad de Roma como Estado, su poder y su majestad. Nos preguntamos en este punto si es ello posible a través de las acciones bélicas de un ejército de ultramar que se encuentra a cientos de kilómetros. La respuesta parece ser afirmativa, pues los intereses de la ciudad del Lacio desde tiempo atrás habían conducido — en concreto desde finales del siglo II a. C.- a la expansión militar por toda la cuenca mediterránea. Ello lleva a que por ese tiempo el poder romano se defienda plenamente en espacios tan distantes como Hispania, Anatolia, Grecia, o el propio norte de África, como es el caso. En esta situación, cuando llegan las malas noticias de Numidia, la ciudad clama por haberse mancillado la gloria impe$r i$, pues hasta el más humilde de los romanos es consciente de cómo las campañas militares mediterráneas que hace décadas se vienen sucediendo suponen un beneficio que, en mayor o menor medida, acaba empapando a todo el sustrato social de Roma.

El presente artículo ha tratado de exponer la expansión romana como una manera de proceder que solo se entiende inserta en un contexto de

\footnotetext{
70 Sall., Iug., 39.1.

${ }^{71}$ Si nos acercamos a la literatura latina respecto al término maiestas, encontramos cómo los antiguos romanos se referirán a la misma con frases como: «maiestas est amplitudo ac dignitas ciuitatis» (Cic., De or., 2.164), «maiestas reipublicae est qua continentur dignitas et amplitudo ciuitatis» (Cic., Her., 4.25.35) o «a magnitudine dicta» (Fest., 31).
} 
fuerte creencia en la superioridad de Roma como comunidad respecto al resto del mundo conocido. Tal pensamiento se verá materializado principalmente por la vía militar, y ello pondrá en un continuo punto de mira crítico las acciones armadas tendentes a tal fin. Hemos comprobado cómo el Derecho se actualiza para perseguir las acciones desleales hacia el Estado, pero también, dentro del ejército, se está vigilante para que las tropas cumplan escrupulosamente con un código militar que, hemos visto, está totalmente vigente y es aplicado con eficacia ante su incumplimiento. 